\title{
From path dependence to policy mixes for Nordic electric mobility: Lessons for accelerating future transport transitions
}

\author{
Kirsi Kotilainen ${ }^{1,2} \cdot$ Pami Aalto $^{1} \cdot$ Jussi Valta ${ }^{1} \cdot$ Antti Rautiainen $^{1} \cdot$ Matti Kojo ${ }^{1}$. \\ Benjamin K. Sovacool ${ }^{3}$
}

Published online: 7 November 2019

(C) The Author(s) 2019

\begin{abstract}
We examine the problem of how to accelerate policies related to electric vehicles (EVs) in the Nordic countries Denmark, Finland, Norway and Sweden. These four Nordic countries represent an interesting collection of cases by virtue of having common decarbonization targets extending to the transport sector, interlinked electric energy systems and a joint electricity market largely based on low-carbon energy while they are open societies bent on innovation, making them well adaptable to a transition toward electric mobility. Our analytical framework drawing from transition research, lock-in and path dependency and institutionalism enables us to discern technological, institutional and behavioral mechanisms which can have both constraining and enabling effects vis-à-vis this transition by means of shaping national socio-technical systems and regimes. On this basis, we also discuss how to develop policies accelerating the transition. We find that the incumbent industries can shape policy choice through the lock-in into institutional inter-dependencies. The accumulation of social and material features, and vested interests of actors, for its part can maintain regime level inertia, impeding the transition. Yet, technological lock-in can also enable EVs, by means of learning effects from technologically interrelated wind energy projects and available infrastructure in buildings that support the EV charging needs. Overall, the complexity of path-dependent mechanisms embedded in the dominant regimes, together with the diversity of emerging policy mixes, demands attention both on the technologies and broader socio-technical systems in order to properly assess the prospects of transition toward electric mobility.
\end{abstract}

Keywords Electric vehicle $\cdot$ Transition policy $\cdot$ Acceleration $\cdot$ Lock-in $\cdot$ Socio-technical regime $\cdot$ Institutions

Kirsi Kotilainen

kirsi.kotilainen@tuni.fi

1 Tampere University, Kalevantie 4, 33100 Tampere, Finland

2 University of Lausanne, 1015 Lausanne, Switzerland

3 University of Sussex, Sussex House, Falmer, Brighton BN19RH, UK 


\section{Introduction}

Policymakers throughout the world face the enduring public policy problem of how to facilitate the proliferation of electric vehicles (EVs). EVs can contribute to the solving of perhaps one of the greatest policy challenges of today-how to lower greenhouse gas (GHG) emissions for passenger vehicles, taken that the transport sector accounts for a $23 \%$ share of global energy-related GHG emissions (IEA 2017). In heavy-duty transport, however, also other solutions alongside vehicle and road electrification are needed in order to decrease emissions, such as biogas options (Pääkkönen et al. 2019). In the passenger vehicle sector, life-cycle assessments indicate that EVs feature more resource effective technology than their main rivals, vehicles using internal combustion engines (ICE). However, these gains depend on the mileage driven, given the environmentally intensive production phase of EVs that includes the processing of minerals for batteries. At the same time, EVs can support the decarbonization of the overall energy system when they use electricity generated in low carbon production (Hawkins et al. 2012). While plug-in hybrid electric vehicles (PHEVs) can contribute to the emission reductions, the overall benefits of battery electric vehicles (BEVs) are even greater since they can provide more flexibility to the energy system than PHEVs, where the share of highly variable generation from renewable sources is increasing, via smart charging, vehicle-to-grid (V2G) technologies and backup solutions for individual buildings through vehicle-to-home (V2H) technologies (Lund and Kempton 2008; Sovacool et al. 2017; Sovacool and Hirsh 2009).

This paper investigates the prospects of introducing policies supporting the proliferation of EVs, arguing that these policies must overcome lock-in at various levels of existing technologies and infrastructures embedded within national energy, transport and building systems, and related path dependencies in the society featuring both material and social facets. For example, the period of global economic growth in the late 1990s and early 2000s brought with it waves of industrialization with heavy investments in technologies and infrastructures throughout the world (Fouquet 2016), much to the favor of ICEs. Overall, the ICE remains at the heart of powerful and widespread socio-technical structures.

In particular, we focus on this interplay of EV policies and the material and social structures shaping their adoption in the context of the Nordic countries Denmark, Finland, Norway and Sweden. These four countries are typical yet diverse cases (Gerring 2013). They are typical in being committed to the EU's $40 \%$ target for GHG emission cuts by 2030, and by having common targets for reaching near-zero emission energy systems by 2050, with major implications for the transport sector. Their interlinked electric energy systems largely based on low-carbon energy and the joint electricity market furthermore create important framework conditions for a transition to EVs. This is because the flexibility gains to the energy system offered by EVs can help them to handle the increasing variability of power production when weather dependent wind power is close to covering half of the annual electric energy supply in Denmark and increases elsewhere. Moreover, flexibility is crucial taken how the cold, dark and long winters, with the slight exception of Denmark, require national energy systems to cope with variance in energy demand and have sufficient reserve power to handle peak demand situations. ${ }^{1}$ Indeed, modeling studies identify EVs, when linked to a smart charging infrastructure, as a cost-efficient part-solution for integrating

\footnotetext{
1 The large hydropower capacities of Norway and Sweden, and the combined heat and power capacities of Denmark and Finland, with Finland's anticipated increased production of nuclear power, can help to balance off the variability.
} 
increasing shares of variable power production into the energy system (Kiviluoma et al. 2018). Finally, the Nordic countries have joint R and D in the field of energy and transport while in terms of institutional theory, they are "open access orders" (Andrews-Speed 2016) whose relatively open access to economic and political power, and rule-of-law alongside high purchasing power of consumers make them well adaptable to a transition toward EVs. $^{2}$

Although the cold climate and sparsely distributed population of the Nordics might appear to dilute some of the advantages of EVs, the demand for coordinated EV policies is high. A report commissioned by the Nordic Council of Ministers proposes a Nordic approach to counter the negative environmental externalities of transport. EVs could play a central role here (Ollila and Skov-Spilling 2017). The Carbon Neutral Scenario of Nordic Energy Research calls for incentives, policies and coordination for increasing the share of EVs to $60 \%$ in the passenger vehicle stock by 2050 (Nordic Energy Technology Perspectives 2016), while the 2019 Declaration on Nordic Carbon Neutrality further highlights electrification as a key solution for emission reduction in this sector (Norden 2019). The International Energy Agency (IEA 2018) notes that the Nordic region is a world leader in the per capita use of EVs, and the third largest market after China and the USA. In 2019, half of new passenger cars sold in Norway were expected to be EVs, with the market in other Nordic countries emerging. The IEA (2018) also highlights the role of public policy and encourages comparative analysis of EV policies.

Hence, a comparative study of these four Nordic countries should equip researchers, planners and policymakers to better assess the more global prospects of accelerated transition to EVs and the required policy mixes-should they fail in this respect, we can expect many others to be even likelier to fail. Yet analysts must also accentuate the differences among the four Nordics. Norway has significant vested interests in the oil and natural gas sector, mostly for export, and Denmark to cover most of domestic consumption and enable minor exports. Finland and Sweden have a robust forestry sector with a vested interest in biofuels; this can erode policy support for EVs (Moe 2015).

While there is a need for comparative study, existing studies are scant. One study uses interviews to outline the variety of policy approaches preferred by Nordic experts (Kester et al. 2018), while a case study of the Norwegian policy successes in EV promotion suggests the same policies may not work in other cases (Figenbaum 2017). Another case study proposes low carbon zones in city centers and for restricting the access of other vehicle types there to pave the way for one-way EVs in particular (Mounce and Nelson 2019). Some studies call for more policy support targeted for low-end adopters of EVs, since they might be more prone to later switch away from BEVs (Hardman et al. 2016). This is because the effectiveness of financial incentives is sensitive to differences in personal income (Mersky et al. 2016). A comprehensive review of studies on EV adoption calls for more comparative research on EV policies (Li et al. 2017). One study comparing 20 countries, among them Norway, finds charging infrastructure pivotal, as well as policies incentivizing EV acquisition financially; even low financial incentives might work in conjunction with well-covering charging facilities (Lieven 2015).

To contribute to this nascent but admittedly growing line of research, we draw upon the literature on lock-in and path dependency (Vadén et al. 2019), as well as institutionalist literature (Andrews-Speed 2016; Moe 2015), which demands greater attention to the

\footnotetext{
${ }^{2}$ Iceland was excluded because of its lack of connection to the Nordic electricity market and highly idiosyncratic electric system based on geothermal power.
} 
vested economic and political interests, and sectoral interest groups maintaining these lockins and path dependencies. Synthesizing these insights with the theories on socio-technical systems, we assume interrelated material and social structures and a wide range of actors to shape the processes of introducing EV policies. This constellation of social and material factors maintains inertia to be countered by means of an appropriate policy mix in order to accelerate the transition to EVs.

We aim to answer the following research questions: (1) How do the material features, lock-in mechanisms and path dependencies of national regimes affect EV policies in the Nordic states? and (2) What can we learn in order to accelerate policies for the decarbonization of mobility? We first outline our analytical and methodological framework, and then move on to our comparative review of the four Nordic cases. Here, we also discuss how the transitions could be accelerated by proactively unlocking the path dependencies of the wider socio-technical system. Finally, we conclude by discussing broader policy and theoretical implications.

\section{Analytical framework: from socio-technical transitions to relevant policy mixes}

Because mobility and EV policies are strongly materially and socially embedded, any coherent analysis of this sphere must be holistic. Our analytical framework builds upon the concepts of lock-in and path dependence, situating them into the wider context of sociotechnical transitions. On this basis, we differentiate between various lock-in types and mechanisms and identify possible types of policies required to create a lock-in supporting EVs or unlocking the constraints of the socio-technical system for such a transition.

\section{The concepts of lock-in and path dependence}

The concept of lock-in refers to a technological pathway or system becoming self-reinforcing. Lock-in has been defined as increasing returns derived from adoption of a certain technology giving incumbent technologies an advantage over new entrants (Arthur 1994). Lock-in eventually causes path dependency, limiting the options of the actors, institutions and networks. Lock-in studies include research on technological change, economics, political science and institutional change. Initially, studies focused on increasing returns and economies of scale of technology adoption (Arthur,1994, 1989; David 1985). Early theorists such as Ellul (1990) observed that patterns of technological change display an autogenerative nature, whereby interlinked institutional and technological imperatives drive the pace and direction of wider social change. Philosopher of technology, Winner (2010), later noted that "technological systems" tend to become highly concentrated and centralized, and may ultimately become institutionally and financially self-supporting.

Path dependence has several interpretations depending on the field of research. For Levi (1997), path dependence means "that once a country or region has started down a track, the costs of reversal are very high. There will be other choice points, but the entrenchments of certain institutional arrangements obstruct an easy reversal of the initial choice." In the formation of path dependence, history matters. Sewell (1996) stated that "what happened at an earlier point in time will affect the possible outcomes of a sequence of events occurring at a later point in time." Some refer to "historical accidents" that can be either small or large (David 1985), others to "positive perceptual biases" limiting future choices (Lee 
and Gloaguen 2015). Furthermore, different scales of path dependence are discernible. According to Martin and Sunley (2006), regional path dependence can be based on natural resources, sunk costs of local assets and infrastructures (heavy industries and physical infrastructures like transport system), local external economies of industrial specialization, regional technological lock-in, economies of agglomeration, region specific institutions, social forms and cultural traditions, inter-regional linkages and inter-dependencies. These elements lead to socio-spatial embeddings that enable or hinder local actors to promote innovations. Diversity of local actors and their power relations influence how innovations emerge locally. In the end, socio-technical transitions include always winners and losers. (Truffer et al. 2015) Kanger et al. (2019) refer to this as a process of "societal embedding" where new innovations must align not only technical elements but cultural discourses, business models, regulations and even transnational standards. Kanger et al. argues that such elements can both entrench existing pathways (e.g., automobility) and actively impede new alternatives (e.g., EVs). Regional path dependence can lead to either a negative lock-in when established industries erode their ability to adjust to new technology or to a positive spatial lock-in leading to clustering and agglomeration of economics.

\section{Lock-in and path dependence in socio-technical transitions}

The concepts of lock-in and path dependence refer to how large-scale socio-technical systems become embedded in society. Energy systems are paradigmatic of the ways in which massive volumes of labor, capital and effort become "sunk" into particular institutional configurations (Scrase and Mackerron 2009). Such strong "path dependencies"-even in early formative conditions which may be historically contingent-can exercise lasting impacts on socio-technical systems, producing inertia (Vadén et al. 2019). Hence, it becomes very difficult to re-orient such path-dependent development (Knox-Hayes 2012).

Studies on socio-technical systems, including the multi-level perspective (Geels 2012), probe into inertia in both social and material forms. This literature originates in the study of technological change and analyzes how niche level innovators seek to introduce new technologies challenging the existing energy regime. This regime, in turn, consists of the rules, practices and skills of the main actors of the energy system influenced by the wider "socio-technical landscape" (Geels 2002). The success of niche level innovators depends on how well they "map" the structures and functions of the regime since incumbents are efficient in nullifying radical changes with incremental improvements. As the market share of the niche grows, technology stretches regime's existing user experience and functionalities (Geels 2005). Emerging niches and aligned landscape pressures start to shape regimes' patterns of consumption, production and governance. For instance, a common strategy for automobile incumbents has been internalizing the threat of niches with early acquisitions and investments in new technologies. (Wells and Nieuwenhuis 2012) Consequently, the interactions between regimes alter and the boundaries between them may vanish (Konrad et al. 2006). Compatibility of technologies leads to positive feedback and momentum for the niche and can help to solve bottlenecks in the development path (Geels 2005).

Further institutional legacies can protect the status quo, including political regulations, tax codes, banking practices and educational institutions. These can all coevolve with the focal system to reinforce particular socio-institutional structures and constituencies (Brown et al. 2007). Extending across sectors as large as the global fossil fuel sector, these political, technological and behavioral forces can "lock-in" otherwise diverse societies into particular structural configurations_-which may then strongly resist re-orientation (Unruh 2000). 
ICEs are part of such large socio-technical systems. The technological and infrastructural lock-in of personal vehicles to the production of petrol and its distribution is capital intensive and features assets with a long life and sunk-cost investments. Furthermore, the traffic and fossil fuel lobbies are large, relatively few in number and well organized in contrast to those advocating change. Regarding these institutional structures, many observers discern a "neoliberal consensus" (a sort of political lock-in) hampering the capacity of governments to introduce strong EV policies. Since this structure prioritizes markets and competition, and since the prices and supporting infrastructure of EVs including charging stations require support and hence remain unfavorable to those of ICEs, vehicles using biofuels or a combination of the two, it is often difficult to design and implement policies in favor of EVs (Scrase and Mackerron 2009).

\section{Lock-in types and mechanisms}

To develop a more detailed conception of lock-in and path dependency in socio-technical transitions, we need to differentiate between various lock-in types and mechanisms. Early research focused on technological lock-in and path dependence stemming from technological innovations (Arrow 1962; Arthur 1994, 1989; David 1985). Later Foxon (2002) distinguished technological lock-in from institutional lock-in. Barnes et al. (2004) further referred to behavioral lock-in consisting of production and consumption habits and usage patterns. Most recently, Fouquet (2016) has differentiated between technological, infrastructural, institutional and behavioral lock-in in the context of energy. Each type comprises different mechanisms explaining how an event-technology choice, institutional commitment or habituation-eventually leads to increasing returns and therefore to path dependency limiting future choices and actions.

Technological lock-in The mechanisms identifiable here include economies of scale, which emerges "when sunk costs from earlier investment in production capacity are spread over an increasing production volume in the socio-technical system," resulting in increasing returns (Arthur 1994; Hughes 1994; Klitkou et al. 2015). This is especially the case with mega-projects, such as electricity or transport systems. Economies of scope can emerge when the technology is widely used; then cost advantages are achieved best by producing a broader range of products (David 1985; Panzar and Willig 1981). For example, niches like electric mobility must compete against established ICE regime equipped with broad sets of products, services and infrastructure. Similarly, technological interrelatedness (Arrow 1962; Arthur 1994; David 1985; Van den Bergh and Oosterhuis 2008) favors the development of complementary and compatible technologies. Learning effects (Arthur 1994) take place both on supply and demand sides. On supply side, they result from learning-by-doing, referring to increasing returns from knowledge accumulation and refined organizations. In this way, higher quality products and incremental innovations become cost-effective. On the consumption side, learning-by-using reduces uncertainty of technology's costs and performance, decreases service costs and increases operation efficiency (Sanden and Azar 2005). Network externalities (David 1985; Katz and Shapiro 1986) emerge when compatibility requirements become standardized. In our context, this could apply for example to EV battery standards and circulation of battery material. However, the incompatibility of new technologies increases demand side inertia as customers benefit more from existing network externalities compared to new technology's better performance (Lee et al. 2003). 
Institutional lock-in The collective action mechanism results from consumption patterns, norms, and customs through coalition building in social networks. Prior to collective action emerging, free riders perceive a lack of incentive to change their habits (Seto et al. 2016). High density of institutions (Pierson 2000) refers to interactions among multiple institutions and to overlapping rules influencing the same behavior. Differentiation of power and institutions (Foxon 2002) and vested interests (e.g., (Boschma 2005; Lovio et al. 2011; Moe 2015) emphasize the ability of strong political actors to impose rules on others. Grabher (1993) described how a political lock-in preserved existing industrial structures and slowed the creative processes and industrial restructuring in the Ruhr area. Complexity and opacity of politics relates to difficulties to link actions and outcomes, making politics highly ambiguous (Foxon 2002; Pierson 2000). Furthermore, institutional learning effects (Foxon 2002) result from increasing adoption of institutions, for example through public procurement, leading to complementary institutions, which increase the efficiency of existing institutions but also create interdependences that are hard to lock-out from (Boschma 2005).

Behavioral lock-in The "irreversibility due to learning and habituation" forms the basis for the behavioral lock-in, as the consumer or producer becomes "stuck" with a product or process due to habits, learning or culture (David 1985). Cognitive costs of switching (e.g., Murray and Haubl 2007; Zauberman 2003) to a new product include learning new skills, rendering skills with earlier product less valuable. Habituation occurs when professionals or consumers develop an attachment to certain products or processes even when better alternatives exist (Barnes et al. 2004). Habits are connected to routines and repetition, and are activated by setting goals on, for instance, product usage (Murray and Haubl 2007). These mechanisms are strengthened by consumers' preference to weigh earlier gains compared to future efforts (Zauberman 2003). Informational increasing returns (Van den Bergh and Oosterhuis 2008) result from technology adoption reaching public attention and stimulating further adoption; more EVs on the roads will eventually raise awareness and consequently interest in EV adoption, although ICEs remain the mainstream choice.

While the lock-in mechanisms can be coupled with certain lock-in types, modern technological systems are deeply embedded in institutional structures and therefore the mechanisms leading to institutional lock-in can influence and strengthen technological path dependence (Foxon 2002). The techno-institutional complex (TIC) suggests a lock into emerge through interactions between technological and institutional systems (Unruh 2000). Furthermore, some lock-in mechanisms are systemic, affecting technological, institutional and behavioral path dependencies. Network externalities, which have positive or negative effect, "arise from systemic relations among technologies, infrastructures, interdependent industries and users" (Foxon 2002). Network externalities can bring huge benefits when they direct investments in sustainable solutions, like in the case of ozone-depleting chlorofluorocarbons (Seto et al. 2016). In their study of road transportation transition in the Nordic countries focusing on e-mobility, advanced biofuels, and hydrogen and fuel cell vehicles, Klitkou et al. (2015) found that several path dependencies had been forced with lock-in mechanisms related to learning effects, economies of scale, economies of scope, network externalities, informational increasing returns, technological, interrelatedness, collective action, institutional learning effects and the differentiation of power. One of their findings concerning the case of battery electric vehicles in Denmark highlighted the role of network externalities, in the form of access to slow and fast charging connections, to be supported by means of new EU technical standards to increase user access and reduce investment costs. See Table 1 for summary of the lock-in mechanisms for different types of lock-in. 
Table 1 Lock-in types and typical mechanisms

\begin{tabular}{|c|c|c|}
\hline Type & Primary lock-in mechanisms & References \\
\hline $\begin{array}{l}\text { Technological (and } \\
\text { infrastructural) }\end{array}$ & $\begin{array}{l}\text { Economies of scale } \\
\text { Economies of scope } \\
\text { Learning effects } \\
\text { Network externalities } \\
\text { Technological interrelatedness }\end{array}$ & $\begin{array}{l}\text { Arthur (1994), Hughes (1994), } \\
\text { Klitkou et al. (2015) } \\
\text { David (1985), Panzar and Willig } \\
\text { (1981) } \\
\text { Arthur (1994) } \\
\text { David, (1985), Katz and Shapiro } \\
\text { (1986) } \\
\text { Arrow (1962), Arthur (1994), David } \\
\text { (1985), Van den Bergh and Oost- } \\
\text { erhuis (2008) }\end{array}$ \\
\hline Institutional & $\begin{array}{l}\text { Collective action } \\
\text { Complexity and opacity of politics } \\
\text { Differentiation of power and institutions } \\
\text { High density of institutions } \\
\text { Institutional learning effects } \\
\text { Vested interests }\end{array}$ & $\begin{array}{l}\text { Seto et al. (2016) } \\
\text { Foxon (2002), Pierson (2000) } \\
\text { Foxon (2002) } \\
\text { Pierson (2000) } \\
\text { Foxon (2002), Boschma (2005) } \\
\text { Boschma (2005), Lovio et al. (2011) }\end{array}$ \\
\hline Behavioral & $\begin{array}{l}\text { Habituation } \\
\text { Cognitive switching costs } \\
\text { Increasing informational returns }\end{array}$ & $\begin{array}{l}\text { David (1985), Barnes et al. (2004), } \\
\text { Zauberman (2003), Murray and } \\
\text { Haubl (2007) } \\
\text { Zauberman (2003), Murray and } \\
\text { Haubl (2007), Van den Bergh and } \\
\text { Oosterhuis (2008) }\end{array}$ \\
\hline
\end{tabular}

\section{Policy types and evolution for low-carbon transitions}

Policies can either create or unlock path dependencies in socio-technological transitions. Policies are often necessary to encourage consumers' adoption of environmental innovations to overcome early market barriers such as inferior functionality or high cost. On the basis of a literature review, we discern four types of public policy instruments. First, command-and-control (regulatory) instruments encompass regulations such as carbon emission restrictions, restrictions for certain types of vehicles, technology and performance standards, feed-in tariffs, and tradable certificates. Second, economic (financial) instruments include emission trading schemes, public investments, tax credits, public funding, and subsidies. Third, education and information (soft) instruments include for example information campaigns or voluntary schemes. Fourth, there are management and planning instruments (Moberg et al. 2019; OECD 2001; Vedung 2017). The policies moreover crisscross the socio-technical landscape, regime and niche levels. In the Nordic context, most of the command-and-control policies spring from macro-level EU directives. Economic, as well as the management and planning instruments are regime level choices; educational and information instruments can also emerge from the niche level.

Policy evolution can be approached in several ways. The "avoid-shift-improve" framework, originally designed to promote widespread climate change mitigation (Creutzig et al. 2018), includes policies that avoid carbon-intensive activities (such as travel), shift practices (for instance to walking or cycling), and improve innovations (such as EVs). A more strategic approach to policy evolution is to consider the policies as instruments for creating new niches or for destabilizing regimes. Path-creation policies can be innovationlinked economic instruments, e.g., R and D support or subsidies for demonstrations. Creative destruction (Schumpeter 1942), or the destructive recreation of incumbent systems 
Fig. 1 Regime lock-in and policy influence on electric mobility transition

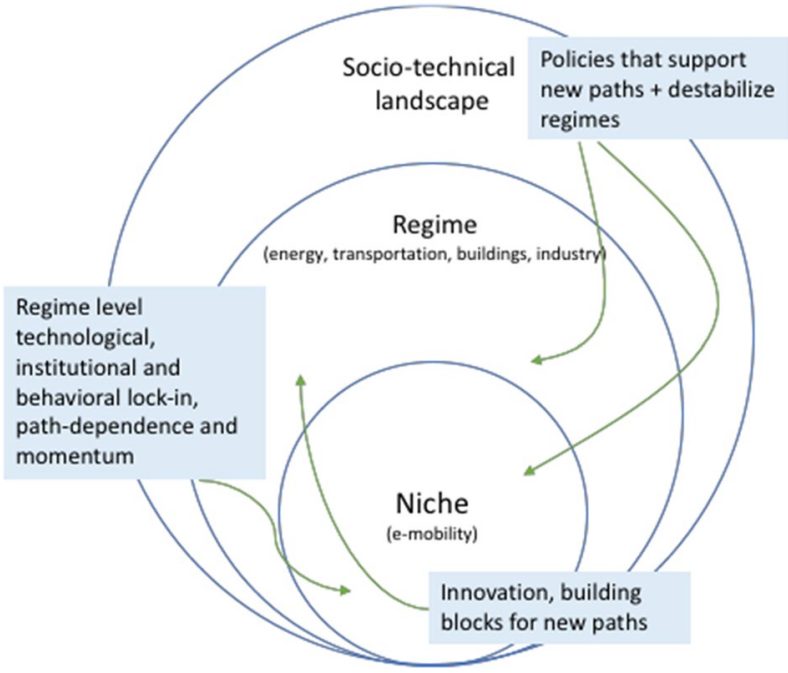

(Johnstone et al. 2017) destabilizes the regime by imposing regulations, sanctions and mandates such as carbon taxes or tailpipe emission regulations (Kivimaa and Kern 2016; Turnheim and Geels 2012). Policies can also sustain or reinforce the existing structures like subsidies for fossil fuel-based transport do. Overall, in practice, policy evolution can proceed through layering, where new instruments and goals complement the old ones; drifting, with new goals while the old instruments remain in use; conversion, when new policies are introduced with old goals kept constant; while replacement introduces new goals and policies (e.g., (Beland 2007). While creative destruction and replacement would arguably be the most effective approaches to regime transition, policy evolution typically occurs incrementally, and rather chaotically, through various cycles of drift, layering and conversion.

In summary, policy making has multiple options to influence path-dependent trajectories in EV policy, but there is no silver bullet. Hence, we explore the concept of lock-in in this context from the policy perspective and identify possible lessons vis-à-vis future transitions (Fig. 1).

\section{Methodological choices}

The bulk of our research consists of documentary review (Saunders et al. 2009), including documents by national, Nordic and EU level governmental institutions, reports by European industry associations, statistics and reports on EV policies, markets and fleet, previous literature on lock-in and path dependency with a reference on the Nordic states, their energy systems, EV markets and policies, news items and reports. Since the unit of analysis is policy, of this material, the governmental documents can be considered primary material, while overall, the relatively heterogeneous material is necessary in this strongly emerging area where both public and private actors are involved. Documentary review is also a commonly accepted approach within the policy studies community (Bernstein and Hoffmann 2018; John 2018; Shim et al. 2015). Our research design had the benefit of drawing from materials in multiple languages, including English but also all the Nordic languages. 


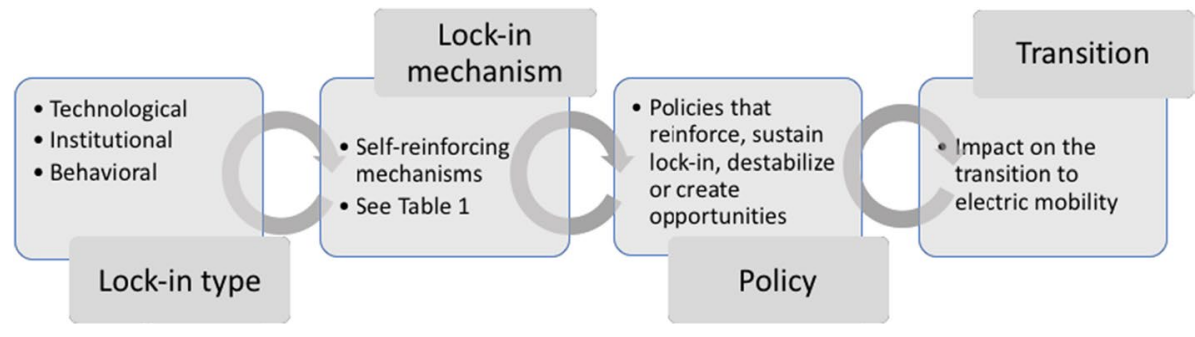

Fig. 2 The analytical framework

Documentary reviews serve three main purposes in this study. First, theoretical review of extant literature covering key concepts of lock-in and path dependency, lock-in mechanisms and policy was conducted. On this basis the analytical framework was developed. Second, EV policy data was collected from governmental documents of Denmark, Finland, Norway and Sweden, recent industry research reports and public databases for the purpose of mapping and comparing current EV policies within a policy mix framework of different policy instrument types. Third, we searched for relevant academic articles and industry reports for the purpose of scoping of the potential lock-in and path dependencies in the context of Nordic energy and transport systems.

The research process had three main stages. First, based on the theoretical documentary review, we developed an analytical framework that first connects the lock-in types to their typical self-reinforcing mechanisms (see Fig. 2). We then associate the lock-in mechanisms with existing policy instruments to examine their influence on the prospects of transition toward EVs in the Nordic states, considering also the nature of the sociotechnical systems. For example, in the case of technology-related lock-in mechanisms, learning effects in the form of accumulated knowledge increase the returns of using a particular technology. The learning effects can be reinforced through macro-level policies in the form of $\mathrm{R}$ and $\mathrm{D}$ funding and infrastructure building, or funding for demonstrations and pilot programs. In the transition to more sustainable transportation, these policies could be related to EV battery or smart charging R and D funding, V2G pilots, or changes in the regulation in order to enable new business models (Lieven 2015).

Second, Nordic EV policy mix mapping and comparison was conducted based on the documentary review. This comparison summarizes the existing EV policies in the Nordic countries.

Third, we proceeded to analyze how the lock-in and path dependency have affected the Nordic EV policies, mindful of how policy analysis usually requires attention on the relevant national contexts and ideologies affecting the successful implementation of certain policies (Dupiuis \& Biesbroek 2013). To increase the validity and reliability of the analysis, internal and external reviews of the results were applied. In the internal reviews, the authors and other academic experts reviewed, discussed and modified the results. Once the results were considered final, the authors invited three experts from Nordic countries to review the results. The reviews took place in Skype calls in which two authors were present: one was discussing the results and the other was taking notes. Minor changes were made after the external review.

Fourth, based on the analysis, the authors summarized the results as learnings on how to accelerate the future transitions. Here, the study of policy learning effects between 
countries can elucidate the key drivers and effects of policy-making (Dodds 2012; Hua et al. 2016).

\section{Results and discussion}

\section{Comparative review of the Nordic EV policy mixes}

Just like climate policies are typically composed of several targets and policy areas (e.g., Abbott 2012), so do EV policies result from several policy streams: energy policy, environmental policy, transport policy, taxation policy, innovation policy and industrial policy. All these are discernible in the Nordic cases (see Table 2), with industrial policy also emerging, in fields such as automation and battery industry (Finland, Sweden, Norway), mining of chemicals and metals needed for batteries (Finland, Sweden) as well as car and truck manufacturing (Finland, Sweden). Each of the types of policy instruments can be found, with some case-specific variation.

Norway's EV policy mix is the broadest, comprising both path-creating and destabilizing instruments, building on the country's society-wide electrification strategy. First EV policies were formulated already in the early 1990s. The policy mix has thereafter consistently strengthened (Figenbaum 2017; Mersky et al. 2016). The command-and-control measures stipulate that only "zero emission vehicles" are to be sold from 2025 while $85 \%$ of government vehicles were to be "zero emission" by 2015 , with highly destabilizing effects for the transport regime. Norway's capital Oslo also supports taxi fleets by installing wireless charging systems (Virki 2019). Economic incentives can also for their part shift users toward EVs, creating new paths. High purchasing price is found to be a major barrier for EV adoption alongside battery range (IEA 2018), together with demographic, environmental and psychological factors ( $\mathrm{Li}$ et al. 2017). Owing to various tax measures, BEVs can be cheaper than ICE vehicles in Norway, which is globally the leading EV market in terms of the sales percentage (Figenbaum 2017; IEA 2018); the use of EVs is also cost efficient with high fuel prices and low electricity prices. The exemption of toll road fees initially incentivized those living in high toll areas (Kester et al. 2018). Furthermore, charging infrastructure, found a "must-have" in a comparison of 20 countries (Lieven 2015), is subsidized and targeted to be available every $50 \mathrm{~km}$ on the main roads. Free parking spaces in urban centers and use of EVs in public transportation lanes represent supporting instruments, but are hardly decisive (Lieven 2015), and must usually be abandoned when the EV fleet grows.

Denmark has a long history of EV policy linked to innovation-based economic instruments, e.g., R and D support or subsidies for demonstrations but no EV specific commandand-control policies apart from the stipulation for $100 \%$ of electric buses in Copenhagen. However, in 2018 the Government proposed a ban on the sale of new fossil fuel powered cars on 2030 and hybrids from 2035. Economic incentives are somewhat paradoxically compromised by the high taxation of electricity as part of the country's energy transition policies where vested interests in wind power feature high (Moe 2015), increasing the operational costs of EVs (IEA 2018). Moreover, Denmark's fluctuating economic incentives have not convincingly shifted behavior or created new paths for EV adoption. Attractive purchase tax exemption accelerated the growth in EV sales until the decision for its gradual abolishment in 2015. Despite the subsequent lengthening of the transition period, the growth of sales remained very low in 2017 (Kester et al. 2018). However, Denmark 


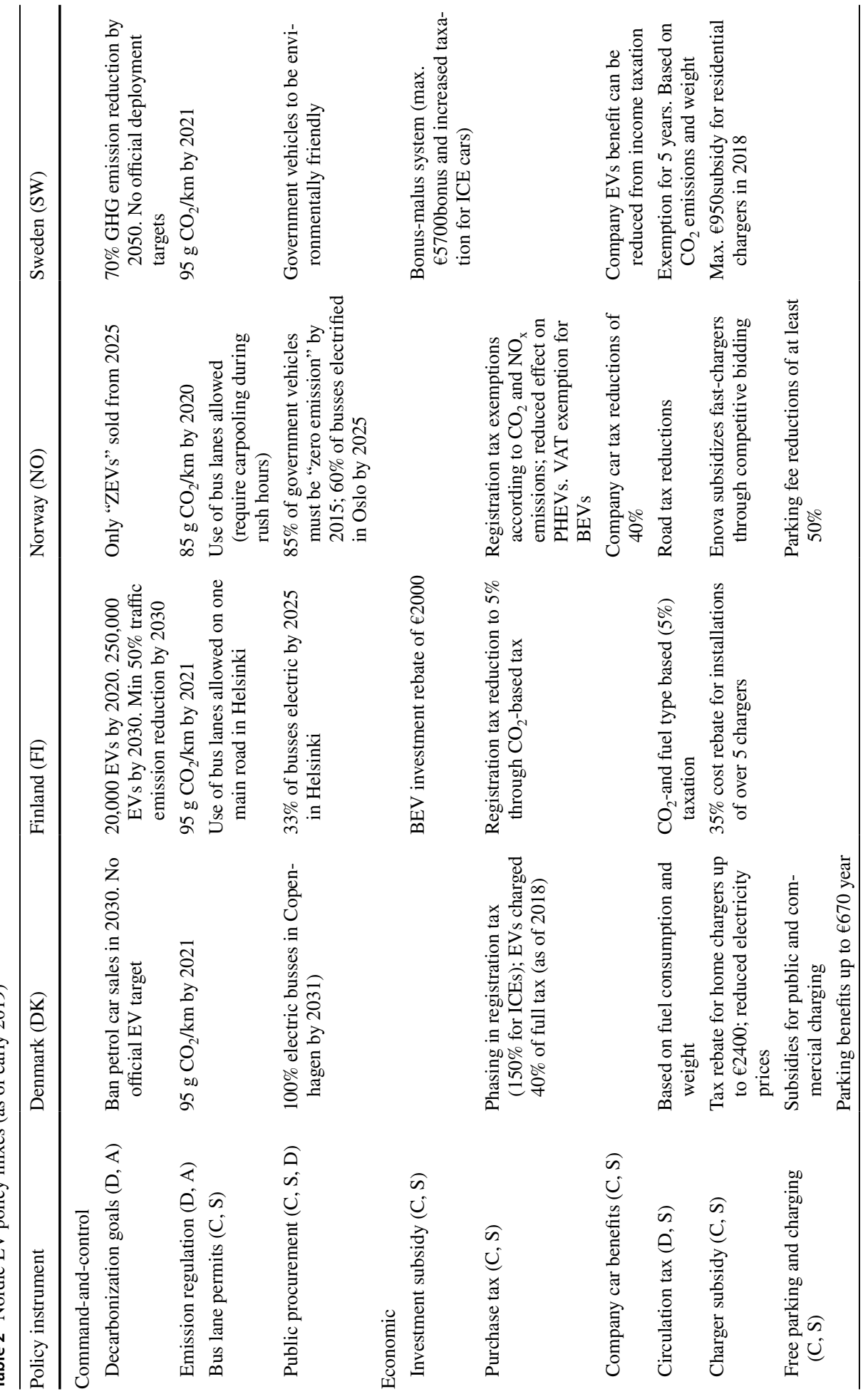




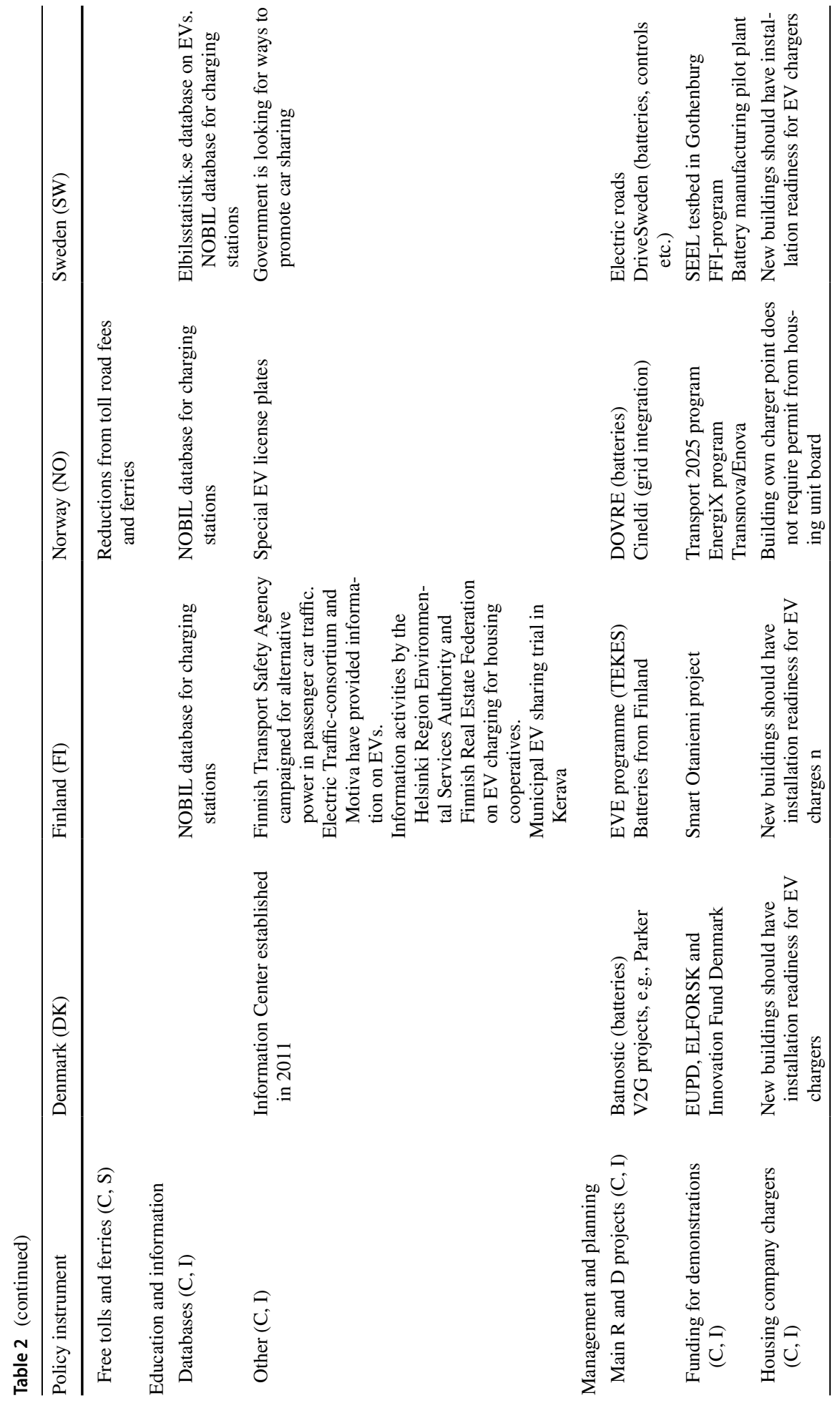




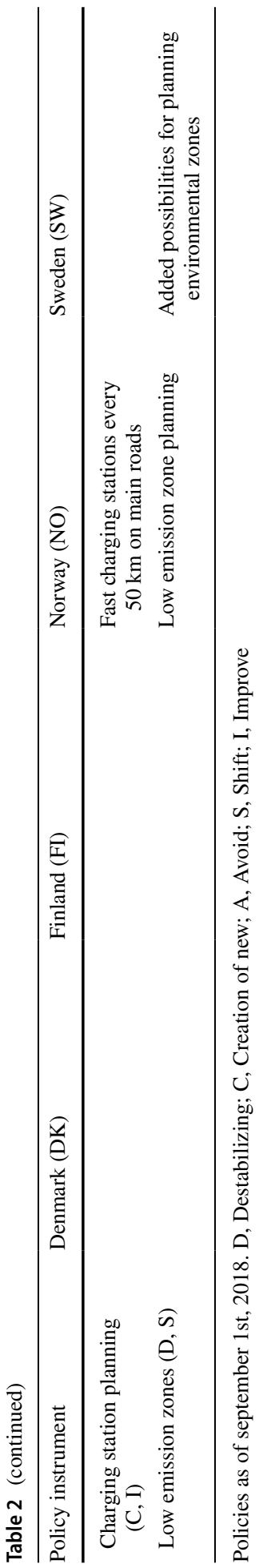

Springer 


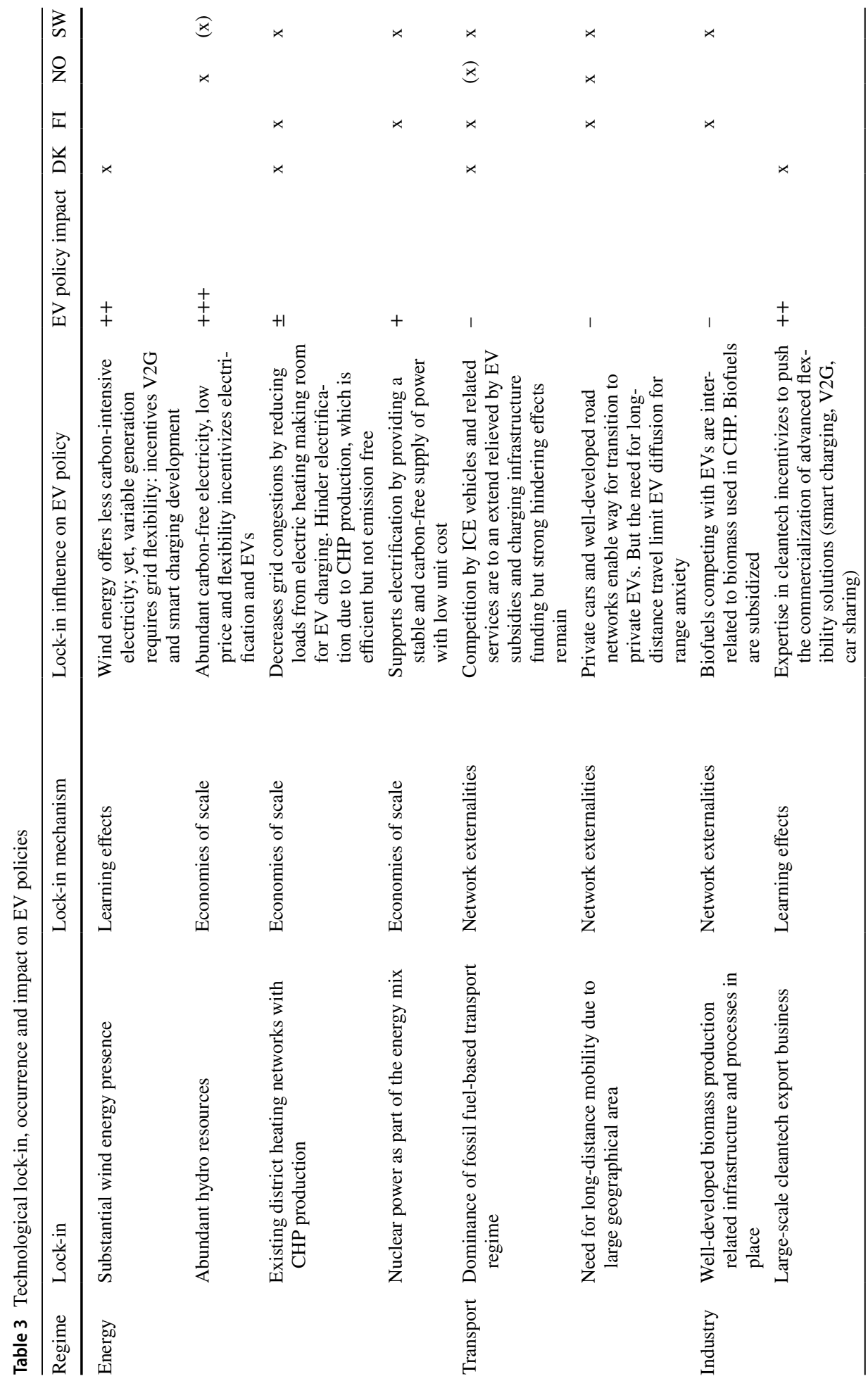




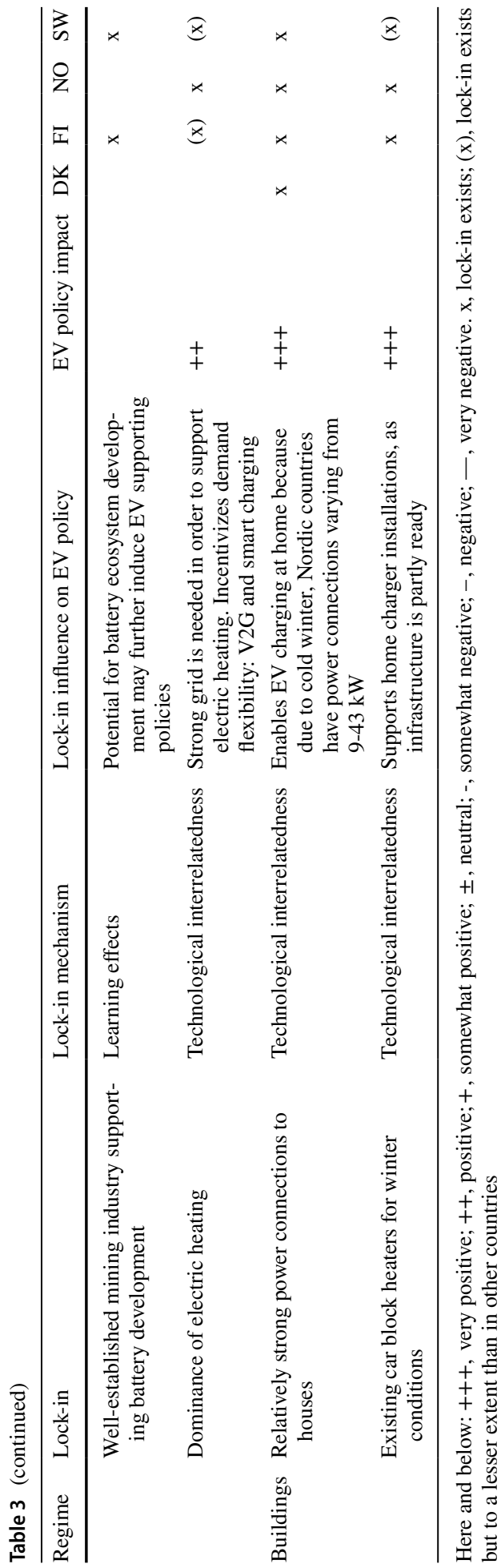


seeks to create new paths by means of management and planning policies, investing in renewable energy and EV integration to the electricity system. This makes it one of the pioneering markets for $\mathrm{V} 2 \mathrm{G}$ demonstrations.

The Swedish EV policies are strong on economic incentives, targeting the adoption phase. A procurement premium was initiated in 2012. From 2018 onwards, the Government offers from 10,000 to 60,000 SEK (€5700) for low emission vehicles, and raises vehicle taxes for ICEs (Transport styrelsen 2018). Today, Sweden has the second largest EV market in the Nordic countries with a fleet of over 50,000 in 2017 (IEA 2018; Insero 2018). Sweden also seeks new paths by supporting the charging infrastructure development and funding R and D on the EV ecosystem. In January 2019, Prime Minister Löfven declared that no new cars with diesel or petrol engine will be sold after 2030 (Regeringsföklaringen 2019).

In Finland, EV policies for long lagged behind the other Nordic states, but the National Energy and Climate Strategy (Government of Finland 2017) and the Medium-Term Climate Plan (Valtioneuvosto 2017) paved the way for eventually firmer command-and-control policies with targets for a 250,000 EV fleet by 2030. In 2018, economic incentives were adopted by means of investment subsidy. In addition, the $\mathrm{CO}_{2}$ based purchase tax favors low emission vehicles. However, the persisting price gap between EV and ICE vehicles partially explains the lower EV adoption rate in Finland compared to the other Nordic states, alongside range anxiety in a country with long distances, combined with the slowly developing charging infrastructure (Ruostetsaari et al. 2016). Many Finnish policies are management and planning type of instruments, e.g., $\mathrm{R}$ and $\mathrm{D}$ programs to develop a battery ecosystem exports, building charging infrastructure and preparing for EV integration to the power grid, e.g., in the form of V2G demonstrations.

\section{Comparative review of the path dependencies, lock-in mechanisms and EV policy implications}

Our analytical framework helps us to explain the EV policy mixes in the four Nordic states in terms of how the underlying lock-in mechanisms support or hinder EV policies, or have other, perhaps indirect externalities or feedback effects on the EV niche.

Technological lock-in (Table 3) are present in each of the regime types-energy, transportation, buildings and incumbent industries.

In Denmark, ramping up of wind power has produced learning effects supporting policies for a more flexible energy system to manage variable energy generation. Denmark also funds demonstrations of V2G solutions that could enable the batteries of EVs as flexibility providers for the energy system. This impact centers more on the $\mathrm{R}$ and $\mathrm{D}$, infrastructure and integration phase rather than on EV adoption, however. Denmark's cleantech exports in a similarly indirect manner create niches for advanced solutions such as smart charging and respective business models.

Other examples of positive energy regime lock-in effects on EVs include Norway's abundant hydro power resources, and old nuclear power capacity in Finland and Sweden that create economies of scale enabling low energy prices, hence incentivizing EV adoption owing to low operating costs.

That the fossil fuel-based transport regime nevertheless remains predominant in Denmark, Finland and Sweden, creates self-reinforcing network externalities favoring the existing system (Sovacool and Axsen 2018). EVs face competition not only from ICEs; the large technical system supporting them causes substantial momentum hindering EV 
adoption. This represents a case of policy layering as ICE and EV policies coexist. Norway, by contrast, is already on the verge of having an EV regime (Figenbaum 2017), owing to its more destabilizing policies replacing the ICE regime.

The path-creation-type policies followed in each of the four states, such as $\mathrm{CO}_{2}$ based vehicle taxes, or funding for EV infrastructure, $\mathrm{R}$ and $\mathrm{D}$ and demonstrations policies facilitate the transition without being decisive. Sweden's substantial economic incentives may, however, yet prove to have destabilizing results.

Industry related lock-ins include biofuels, building on existing infrastructure and processes in the pulp and paper industries, and fuel refineries, through positive externalities. Nordic countries, with the exception of Norway, can be described as potent bioenergy economies having access to a mix of forest products, agricultural residues and animal manure, paper and pulp, and other forms of biomass. Importance of bio economy leads to strategies and policies in favor of biomass related energy including biofuel. Biofuels are hence high policy priorities, especially in Finland and Sweden, receiving subsidies, which creates competition for EV incentives. However, the use of advanced biofuels, such as liquefied biogas, in heavy transport, aviation or maritime transport can contribute to reduced emissions from the transport sector, and hence offers a potentially sustainable option to electricity especially in these segments. Simultaneously, buildings in the Nordic states are equipped with strong power connections enabling block heaters used during the cold winter months to pre-heat the cars. This technological interrelatedness paves way to EV charging at homes and offices. Policy support for residential charging infrastructure investments exists in all Nordic states.

Institutional lock-in (Table 4) interlink incumbent industry regimes with the transport regime through the high density of institutions, vested interests and asymmetries of power. For example, the vested interests of the pulp and paper, and fuel refinement industries reinforce the technological lock-in effects of biofuels in Finland and Sweden.

Asymmetries of power for their part allow established industry actors to successfully lobby for subsidies maintaining the dominance of fossil fuel-based regimes. Finland, for example, uses economic instruments to subsidize the use of fossil fuels in the transport sector through various indirect mechanisms annually with some 1.8 billion $€$ (Hyyrynen 2013). This creates strong inertia for electrification in all sectors. In Norway the incumbent fossil fuel regime is interlinked with the transport regime through a very differently functioning institutional mechanism, as part of the tax income from the exporting-based incumbent fossil fuel industries can be directed to measures supporting EV adoption. Figenbaum (2017) also argued that not having own domestic ICE vehicle production decreased opposition to Norwegian BEV subsidies.

Substantial citizen ownership in Denmark's energy sector strengthens bottom-up mobilization and collective action that in turn support e.g., energy cooperatives and communities. This forces decision makers to remove barriers from collective and private energy ownership models while self-generated electricity can support EV adoption by offering lower cost EV charging at homes.

Furthermore, in Denmark the high consumer acceptance of new renewable energy creates increasing informational returns that support EV adoption by means of prompting policy makers to introduce economic incentives for consumers producing their own electricity usable for EV charging. This and other behavioral lock-in pertain to generic and well-known patterns of culture, society and informal institutions (Table 5).

At the same time, a deeply embedded habituation mechanism locks a considerable part of Danes into cycling, which naturally is a sustainable solution. However, 


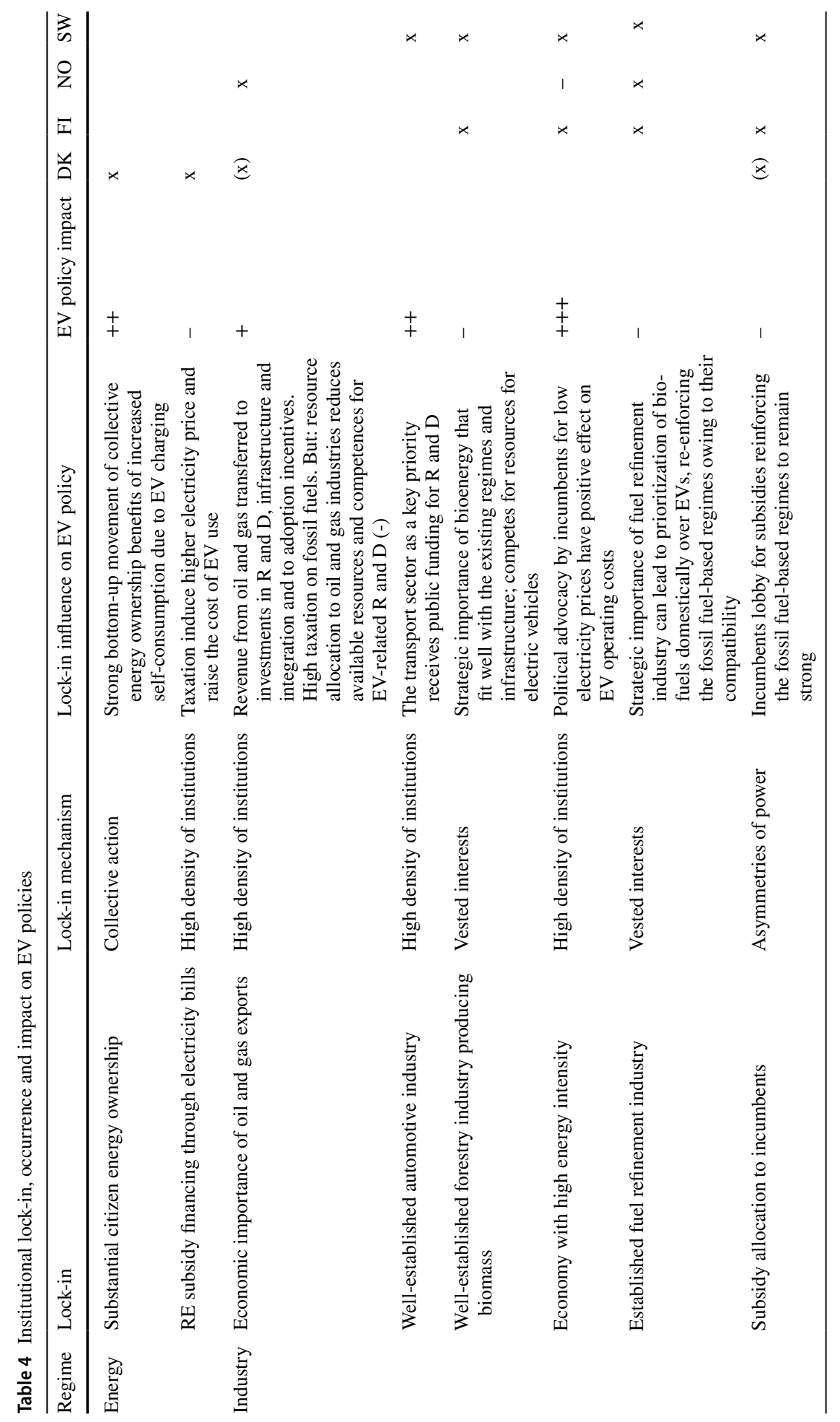




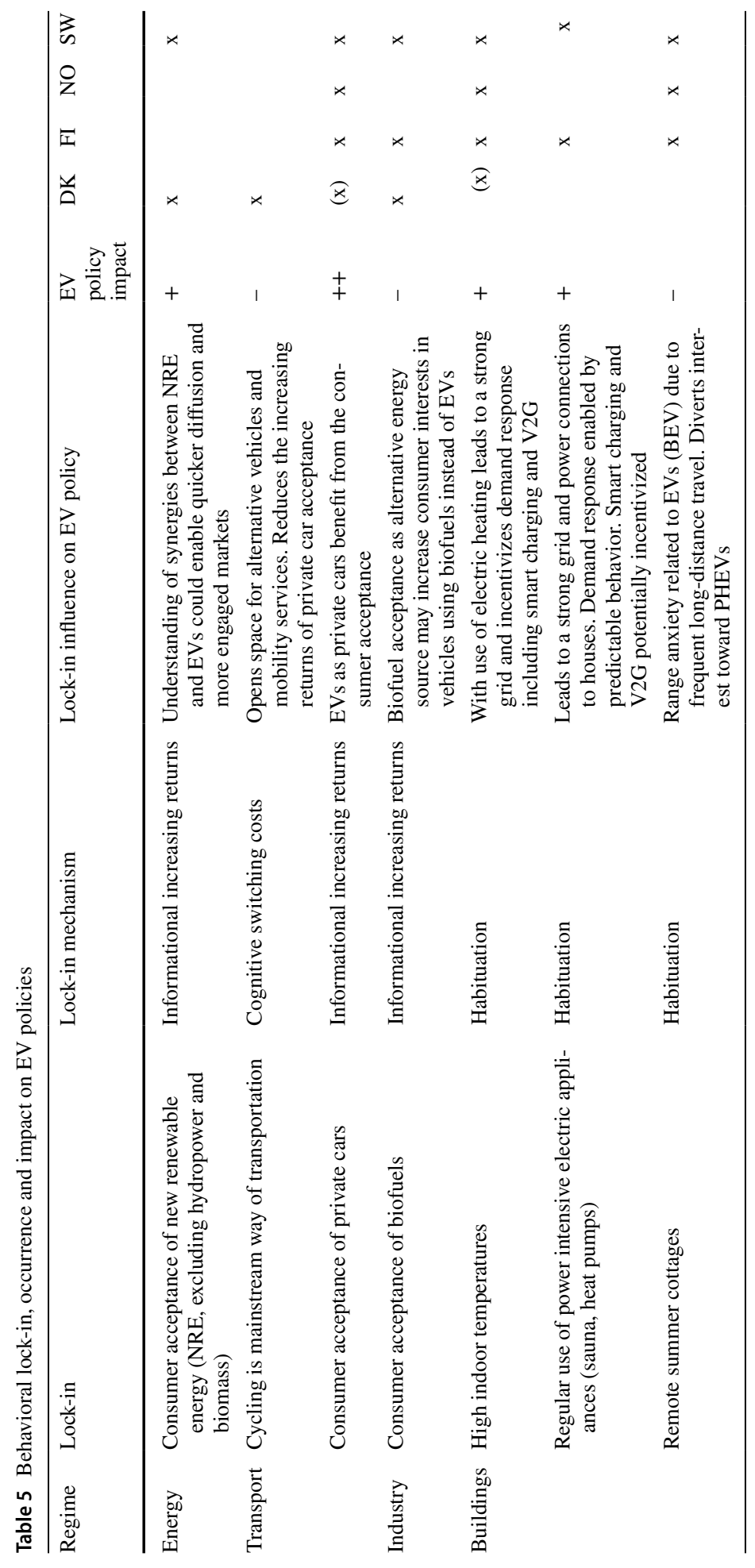


overcoming the associated cognitive switching costs require very high value proposition in favor of EVs. Yet the end result is mixed for EV adoption.

Finns and Swedes are habituated to relatively high indoor temperatures, which reinforces the requirements for a strong electricity grid and may facilitate policy support for integrating EVs into the grid. Yet these V2G policies so far target mostly R and D, infrastructure and system integration rather than consumer involvement.

The Nordic citizens are also known for their holiday homes in remote locations. In a survey conducted in 2007, 22-31\% of Finnish, Swedish and Norwegians told they have a second home (Steineke 2007). Naturally, this reinforces range anxiety, one of the adoption barriers for EVs. Educational and informational campaigns combined with funding for charging infrastructure and development of faster charging solutions can help, but we estimate the impact on EV adoption overall to be negative.

\section{How to accelerate the future transitions?}

With our comparative review of the Nordic EV policies, lock-in and the underlying mechanisms, we can now return to our second research question on how to accelerate the decarbonization of mobility. The following policy recommendations and discussion highlight our findings in this regard.

1. Path-creation policies are predominant in the Nordic policy mixes but are unlikely to be decisive on their own We mostly found policies creating new paths for mobility but also some regime destabilizing and sustaining policies. While both path-creation and destabilizing policies are needed (Kivimaa and Kern 2016), we suggest that in this field, destabilizing decarbonization policies, for example restricting polluting technologies, are potentially more consequential for purposes of accelerating the transition. Norway's stipulation for only EVs to be sold from 2025 exemplifies a landmark regime destabilizing command-and-control policy. Other command-and-control measures like carbon tailpipe taxes are so far used sparingly in the Nordic states, making them less radical "avoid" type policies. Moreover, Finland seeks to modify the transportation regime by means of a new Transport Service Act facilitating innovative business models and easier entry into the transportation services sector; this destabilizes the regulation of the transport regime but in terms of EV adoption-which also depends on the energy, industry and buildings regime, as well as the niches created - it is more a "shift" or "improve" type policy. Furthermore, each of the Nordic states uses various economic instruments to gradually shift the vehicle fleet toward EVs and to enable related technologies and services to grow. We also observed a swift effect from the policy change reducing economic support for EVs in Denmark in 2015. "Improve" type policies for their part are most in evidence in the form of education and information campaigns.

2. More systematic cross-regime policy approach is required Merely looking at the "EV policies proper" is insufficient for purposes of forming a more holistic picture due to spill-over effects from beyond the transport regime. On the level of the energy regime, the prevailing large subsidies maintain the fossil fuel-based system, while on the building regime level, city planning and housing policies are linked to the prospects of $\mathrm{V} 2 \mathrm{G}$ and $\mathrm{V} 2 \mathrm{H}$. We hence suggest that governments should evaluate the policy mixes more systematically to understand the compounded effects of multiple regimes in the transition toward EVs. 
3. Technology neutral approach causes confusion The lock-in effects sustaining the biofuels industry can induce negative externalities on EVs. Here, the interplay between industry, energy and transportation regimes and the related institutions is crucial. The pulp and paper industries seek positive externalities in the transportation and energy sectors to support the side products of their production processes and to increase their profitability. While the first-generation biofuels raise concerns over e.g., extensive use of palm oil, advanced biofuels and electric vehicles both serve transportation needs, yet the two have different intermediaries. We hence agree that technology neutral policies typical of transition management, whereby governments wait for the market to make the selection, are unlikely to deliver fast enough the required decarbonization outcomes (Meadowcroft 2009). Instead, policies should differentiate between the use of biofuels and EVs: Biogas and biofuels could be incentivized in domains, like aviation, where they do not compete with EVs. They could more decisively be targeted at heavy transport with electrification preferred in the passenger vehicles sector. Our finding of the regional lock-in among the bioenergy clusters in Finland and Sweden is relevant here. Nordic states cooperate closely on energy market issues, but increased coordination of policies on the regional level could help to direct the development faster toward decarbonization.

4. Focus on planning and management To improve the layering of EV policies, governments can reduce competition between the different paths toward low emission transportation. For that end, we argue that existing industries supporting the EV niche should be incentivized to shift resources to produce and complement functions related to EVs. In this respect the Norwegian system in which the proceeds from the oil and natural gas industries help to finance the transition, is only a start. Even there, more focus on resource availability for new technology $\mathrm{R}$ and $\mathrm{D}$ is required. The building industry could be incentivized to promote the installation of home charging infrastructure while housing companies could facilitate car sharing practices, alongside the current focus on station and street-parking based car sharing platforms (Mounce and Nelson 2019). IT and telecommunications sectors could play a critical complementing role. While Kester et al. (2018) find a need for enhanced information activities, we suggest an even wider focus on planning and management policies to facilitate interactions between these sectors to accelerate the transition.

5. Improve cross-institutional cooperation We found that improved layering of policy and the call for policy mixes (Kivimaa and Kern 2016) hit the constraints of the high density of institutions affecting the EV policies. This can result in contradicting policy decision making, on one front supporting EV transition and on other hindering it. For instance, policy choices do not only concern how to fill the gap that opens from decreasing tax revenue from ICE vehicles, but also how to tax EVs appropriately. In Denmark, policy incentives drive renewable energy transition, EV adoption and EV-grid integration but EV operation costs are higher compared to other countries due to high energy taxation as part of the country's transition policies. Institutional learning effects may gradually shape policy making, but improved cross-institutional coordination could help to optimize policy layering.

6. Create complementarities through widespread electrification Based on the identified lock-ins, we found that incentives for the electrification of the society support EVs. Using electricity instead of gas and oil in buildings yields an infrastructure facilitating EV charging and offers flexibility to energy systems with more intermittent power. Similarly, the vested interests of the energy intensive industry can help to keep electricity prices low, unless their interests are protected by industry-targeted taxation benefits. 
Low electricity prices can make the value proposition of EV ownership clearer compared to ICEs. The risk in this positive externality is that it can lead to increased usage of resources instead of saving them by incentivizing increased utilization of personal transportation.

7. Use a mix of strategies to unlock behavioral patterns Breaking behavioral lock-in with regulatory and economic instruments is difficult. Therefore, we suggest resources to be also assigned toward enabling infrastructure and informational and educational projects paving the way for less environmentally harmful consumption. Other options include the further acceleration of the "societal embedding" of EVs across different contexts (Kanger et al. 2019). Suitable policies utilize management and planning, as well as informational instruments for instance via better articulation and marketing materials, targeting changing cultural perceptions (such as the decreasing interest in car ownership and driving licenses among the younger demographic), or fostering the integration of policies and investments (e.g., national programs to revamp transport, energy, and housing systems). Policies should target a broader mass of consumers, with stronger user engagement, approach users not only as "buyers" of technologies, and instead articulate new routines, behavioral practices and norms.

\section{Conclusions}

Our analytical framework stitched together technological, institutional and behavioral path dependencies with lock-in mechanisms and policy mixes. We then applied this framework to four countries in the Nordic region and identified several lock-in mechanisms shaping the national policy mixes for EV adoption. Our analysis particularly underscored the incumbent industries' substantial influence on EV policy mixes, especially through institutional inter-dependencies. The accumulation of social and material features, and vested interests of actors, was found to maintain regime level inertia and impede the transition to EVs.

Our comparison of the four Nordic cases testifies to the importance of EV-related regimes to be able to bring complementarities and benefit out of EV adoption even in highly potent cases for transition. Various lock-ins exist in different forms across countries globally. They need to be tackled by means of appropriate policy mixes. In other words, accelerated transition to EVs is unlikely to take place on the basis of technology neutrality or market-only policies but requires policies capitalizing on complementary elements in order to overcome vested interests in competing solutions and build legitimacy for EV solutions.

While the constellations of lock-in mechanisms, vested interests, the socio-technical systems in which they are embedded, and policy mixes we have examined are case-specific, our categorizations are if not universal, at least highly generalizable. This increases the applicability of our analytical framework to further cases. In this regard, we argued that the three lock-in types can have different implications on policies. Yet we found the technological types of lock-in influence each of the other observed regimes, although the energy regime even more so than the building and transport regimes. Here the impact on EV policies was mainly supportive. The institutional lock-ins were strongly connected to incumbent industries, and were mainly found to hinder EV transition. The behavioral lockin shaped EVs in varying ways through buildings and transport sector related policies. 
Further comparisons on other, both highly and less potent cases vis-à-vis EV transition will be useful to complement and validate our results on the interrelationships between the lock-ins, policies and outcomes in order to accelerate future transitions elsewhere.

Finally, the compelling complexity of lock-in mechanisms, coupled with the diversity of emerging policy mixes, reminds us that attention should not only focus on discrete technologies, but also on broader socio-technical systems. This would include complementary technologies like other forms of electric mobility (e-bikes, e-freight, etc.), charging facilities for BEV and storage facilities, backup capacity and smart grids for renewable electricity. But it also means focusing on comprehensive local transport systems and spatial planning rather than only on bicycles or trams, as well as the complex and interstitial policy mixes behind electricity, energy, buildings, and mobility. Thus, our study offers a valuable heuristic view to socio-technical innovation and diffusion, which is a core challenge for addressing climate change in the coming decade.

Acknowledgements The authors thank Mads Greaker, Oslo Metropolitan University, Olaf Samuelson, Lund University and Yingkui Yang, University of Southern Denmark for reviewing and commenting Tables 3-5. This research has been funded by Strategic Research Council at the Academy of Finland, project "Transition to a Resource Efficient and Climate Neutral Electricity System (EL-TRAN)" (Grant No. 314319).

Additional data Data sources related to Tables 2-5 can be found online: Data sources to https://drive.googl e.com/file/d/1ZtnV6VcWPRX6I-KA8wAOaN2eae-13qXf/view?usp=sharing

\section{Compliance with ethical standards}

Conflict of interest The authors declare that there are no conflicts of interest.

Open Access This article is distributed under the terms of the Creative Commons Attribution 4.0 International License (http://creativecommons.org/licenses/by/4.0/), which permits unrestricted use, distribution, and reproduction in any medium, provided you give appropriate credit to the original author(s) and the source, provide a link to the Creative Commons license, and indicate if changes were made.

\section{References}

Abbott, K. W. (2012). The transnational regime complex for climate change. Environment and Planning C: Government and Policy, 30(4), 571-590.

Andrews-Speed, P. (2016). Applying institutional theory to the low-carbon energy transition. Energy Research \& Social Science, 13, 216-225.

Arrow, K. J. (1962). The Economic Implications of Learning by Doing. The Review of Economic Studies, 29(3), 155-173.

Arthur, W. B. (1989). Competing technologies, increasing returns, and lock-in by historical events. The Economic Journal, 99(394), 116-131. https://doi.org/10.2307/2234208.

Arthur, W. B. (1994). Increasing returns and path dependence in the economy. Ann Arbor: University of Michigan Press.

Barnes, W., Gartland, M., \& Stack, M. (2004). Old habits die hard: Path dependency and behavioural lockin. Journal of Economic Issues, 38(2), 371-378.

Beland, D. (2007). Ideas and institutional change in social security : conversion, layering, and policy drift. Social Science Quarterly, 88(1), 20-38.

Bernstein, S., \& Hoffmann, M. (2018). The politics of decarbonization and the catalytic impact of subnational climate experiments. Policy Sciences, 51(2), 189-211.

Boschma, R. A. (2005). Proximity and innovation: A critical assessment. Regional Studies, 39(1), 61-74. https://doi.org/10.1080/0034340052000320887.

Brown, M. A., Chandler, J., Lapsa, M. V, \& Sovacool, B. K. (2007). Carbon lock-in: barriers to deploying climate change mitigation technologies. ORNL/TM-2007/124. Oak Ridge. https://doi.org/10.1016/j. jngse.2014.08.025 
Creutzig, F., Roy, J., Lamb, W. F., Azevedo, I. M. L., Bruine De Bruin, W., Dalkmann, H., et al. (2018). Towards demand-side solutions for mitigating climate change. Nature Climate Change, 8(4), 268-271. https://doi.org/10.1038/s41558-018-0121-1.

David, P. A. (1985). Clio and the economics of qwerty. American Economic Review.

Dodds, A. (2012). Comparative public policy. London: Palgrave Macmillan.

Dupiuis, J., \& Biesbroek, G. R. (2013). Comparing apples and oranges: The dependant variable problem in comparing and evaluating climate change adaptation policies. Global Environmental Change, 23, 1476-1487.

Ellul, J. (1990). The Technological Bluff. Grand Rapids, MI: William Erdman and Company.

Figenbaum, E. (2017). Perspectives on Norway's supercharged electric vehicle policy. Environmental Innovation and Societal Transitions, 25, 14-34. https://doi.org/10.1016/j.eist.2016.11.002.

Fouquet, R. (2016). Path dependence in energy systems and economic development. Nature Energy, 1(8), 16098. https://doi.org/10.1038/nenergy.2016.98.

Foxon, T. J. (2002). Technological and institutional 'lock-in' as a barrier to sustainable innovation. Imperial College Centre for Policy and Technology Working Paper. http://www.iccept.ic.ac.uk

Geels, F. W. (2002). Technological transitions as evolutionary reconfiguration processes: a multi-level perspective and a case-study. Research Policy, 31, 1257-1274. https://doi.org/10.1016/s0048 -7333(02)00062-8.

Geels, F. W. (2005). Processes and patterns in transitions and system innovations: Refining the co-evolutionary multi-level perspective. Technological Forecasting and Social Change, 72(6), 681-696. https://doi.org/10.1016/j.techfore.2004.08.014.

Geels, Frank W. (2012). A socio-technical analysis of low-carbon transitions: introducing the multilevel perspective into transport studies. Journal of Transport Geography, 24, 471-482. https://doi. org/10.1016/j.jtrangeo.2012.01.021.

Gerring, J. (2013). Whatis a case study and what is it good for? American Political Science Review, 98(2), 341-354.

Grabher, G. (Ed.) (1993). The weakness of strong ties-the lock-in of regional development in the Ruhrgebeit. In The embedded firm: on the socioeconomics of industrial networks. London: Routledge

Hardman, S., Siu, E., \& Steinberger-Wilckens, R. (2016). Comparing high-end and low-end early adopters of battery electric vehicles. Transportation Research Part A, 88, 40-57.

Hawkins, T. R., Singh, B., Majeau-bettez, G., \& Strømman, A. H. (2012). Assessment of conventional and electric vehicles. Journal of Industrial Ecology, 17(1), 53-64. https://doi.org/10.111 1/j.1530-9290.2012.00532.x.

Hua, Y., Oliphant, M., \& Hu, E. J. (2016). Development of renewable energy in Australia and China: A comparison of policies and status. Renewable Energy, 85, 1044-1051. https://doi.org/10.1016/j. renene.2015.07.060.

Hughes, T. (1994). Technological momentum. In M. R. Smith \& L. Marx (Eds.), Does technology drive history? The dilemma of technological determinism. Cambridge: MIT Press.

Hyyrynen, M. (2013). Ympäristön kannalta haitalliset tuet (Vol. 13). Ympäristöministeriö.

IEA. (2017). Global EV Outlook 2017: Two million and counting. Paris: International energy agency (IEA). https://doi.org/10.1787/9789264278882-en.

IEA. (2018). Nordic EV Outlook 2018: Insights from leaders in electric mobility. Paris: International energy agency (IEA).

Insero. (2018). An overview of the Nord electric vehicle market with the latest sales figures, infrastructure overview, and the main market tendencies. Insero Quarterly Q2 2018. https://insero.com/media /4925/insero-quarterly-2018-q2.pdf?utm_source=newsletter\&utm_medium=email\&utm_campa ign=iq_q2. Accessed 5 Nov 2019.

John, P. (2018). Theories of policy change and variation reconsidered: a prospectus for the political economy of public policy. Policy Sciences, 51(1), 1-16.

Johnstone, P., Stirling, A., \& Sovacool, B. (2017). Energy research and social science policy mixes for incumbency: Exploring the destructive recreation of renewable energy, shale gas 'fracking,' and nuclear power in the United Kingdom. Energy Research \& Social Science, 33, 147-162. https://doi. org/10.1016/j.erss.2017.09.005.

Kanger, L., Geels, F., Sovacool, B. K., \& Schot, J. W. (2019). Technological diffusion as a process of societal embedding: Lessons from historical automobile transitions for future of electric mobility. Transportation Research Part D. (in press)

Katz, M. L., \& Shapiro, C. (1986). Technology adoption in the presence of network externalities. Journal of Political Economy, 94(4), 822-841. 
Kester, J., Noel, L., Zarazua de Rubens, G., \& Sovacool, B. K. (2018). Policy mechanisms to accelerate electric vehicle adoption: A qualitative review from the Nordic region. Renewable and Sustainable Energy Reviews, 94, 719-731. https://doi.org/10.1016/j.rser.2018.05.067.

Kiviluoma, J., Rinne, E., \& Helistö, N. (2018). Comparison of flexibility options to improve the value of variable power generation. International Journal of Sustainable Energy, 37(8), 761-781. https://doi. org/10.1080/14786451.2017.1357554.

Kivimaa, P., \& Kern, F. (2016). Creative destruction or mere niche creation? Innovation policy mixes for sustainability transitions. Research Policy, 45(1), 205-217. https://doi.org/10.1016/j.respo 1.2015.09.008.

Klitkou, A., Bolwig, S., Hansen, T., \& Wessberg, N. (2015). The role of lock-in mechanisms in transition processes: The case of energy for road transport. Environmental Innovation and Societal Transitions, 16, 22-37. https://doi.org/10.1016/j.eist.2015.07.005.

Knox-Hayes, J. (2012). Negotiating climate legislation: Policy path dependence and coalition stabilization. Regulation and Governance, 6(4), 545-567. https://doi.org/10.1111/j.1748-5991.2012.01138.x.

Konrad, K., Voß, J.-P., \& Truffer, B. (2006). Transformations in consumption and production patterns from a regime perspective. In Perspective on radical changes to sustainable consumption and production, Workshop of the SCORE (pp. 439-458). www.score-network.org

Lee, J., Lee, J., \& Lee, H. (2003). Exploration and exploitation in the presence of network externalities. Management Science, 49(4), 553-570.

Lee, R. P., \& Gloaguen, S. (2015). Path-dependence, lock-in, and student perceptions of nuclear energy in France: Implications from a pilot study. Energy Research \& Social Science, 8, 86-99.

Levi, M. (1997). A model, a method, and a map: Rational choice in comparative and historical analysis. In M. I. Lichbach \& A. S. Zuckerman (Eds.), Comparative politics: Rationality, culture, and structure. Cambridge: Cambridge University Press.

Li, W., Long, R., Chen, H., \& Geng, J. (2017). A review of factors influencing consumer intentions to adopt battery electric vehicles. Renewable and Sustainable Energy Reviews, 78, 318-328. https://doi. org/10.1016/j.rser.2017.04.076.

Lieven, T. (2015). Policy measures to promote electric mobility-A global perspective. Transportation Research Part A: Policy and Practice, 82, 78-93. https://doi.org/10.1016/j.tra.2015.09.008.

Lovio, R., Mickwitz, P., \& Heiskanen, E. (2011). Path dependence, path creation and creative destruction in the evolution of energy systems. In R. Wüstenhagen \& R. Wuebker (Eds.), The handbook of research on energy entrepreneurship (p. 274). Edward Elgar Publishing.

Lund, H., \& Kempton, W. (2008). Integration of renewable energy into the transport and electricity sectors through V2G. Energy Policy, 36(9), 3578-3587. https://doi.org/10.1016/j.enpol.2008.06.007.

Martin, R., \& Sunley, P. (2006). Path dependence and regional economic evolution. Journal of Economic Geography, 6(4), 395-437. https://doi.org/10.1093/jeg/lb1012.

Meadowcroft, J. (2009). What about the politics? Sustainable development, transition management, and long term energy transitions. Policy Sciences, 42, 323-340. https://doi.org/10.1007/s11077-009-9097-z.

Mersky, A. C., Sprei, F., Samaras, C., \& Qian, Z. (2016). Effectiveness of incentives on electric vehicle adoption in Norway. Transportation Research Part D, 46, 56-68.

Moberg, K. R., Aall, C., Dorner, F., Reimerson, E., Ceron, J. P., Sköld, B., et al. (2019). Mobility, food and housing: responsibility, individual consumption and demand-side policies in European deep decarbonisation pathways. Energy Efficiency, 12(2), 497-519.

Moe, E. (2015). Renewable energy transformation of fossil fuel backlash: Vested interests in the political economy. New York: Palgrave Macmillan.

Mounce, R., \& Nelson, J. D. (2019). On the potential for one-way electric vehicle car-sharing in future mobility systems. Transportation Research Part A, 120, 17-30.

Murray, K. B., \& Haubl, G. (2007). Explaining cognitive lock-in: The role of skill-based habits of use in consumer choice. Journal Of Consumer Research, 34(1), 77-88. https://doi.org/10.1086/513048.

Norden. (2019). Stepping up Nordic Climate cooperation. https://www.norden.org/en/news/stepping-nordi c-climate-co-operation. Accessed 5 Nov 2019.

Nordic Energy Technology Perspectives 2016. (2016). Paris, France. https://doi.org/10.1787/9789264257 665-en

Ollila, J., \& Skov-Spilling, J. (2017). Pohjoismainen energiayhteistyö: Vahva tänään-vahvempi huomenna (Vol. 2017735). Copenhagen: Nordic Council of Ministers.

Pääkkönen, A., Aro, K., Aalto, P., Konttinen, J., \& Kojo, M. (2019). The Potential of biomethane in replacing fossil fuels in heavy transport-A case study on Finland. Sustainability, 11(17), 4750. https://doi. org/10.3390/su11174750. 
Panzar, J. C., \& Willig, R. D. (1981). Economies of scope. The American Economic Review, 71(2), $268-272$.

Pierson, P. (2000). Increasing returns, path dependence, and the study of politics. The American Political Science Review, 94(2), 251-267.

Regeringsföklaringen. (2019). Regeringsförklaring avgiven av statsminister Stefan Löfven.

Ruostetsaari, I., Aalto, P., Kallioharju, K., Kojo, M., RautiainenA., \& Toivanen, P. (2016). Suomalaiset eivät lämpene sähköautoille-miten kiinnostus sytytetään? https://el-tran.fi/analyysit/

Sanden, B. A., \& Azar, C. (2005). Near-term technology policies for long-term climate targets economy wide versus technology specific approaches. Energy Policy, 33(12), 1557-1576. https://doi. org/10.1016/j.enpol.2004.01.012.

Saunders, M., Lewis, P., \& Thornhill, A. (2009). Research methods for business students. Harlow, England: Pearson Education.

Schumpeter, J. A. (1942). Capitalism, socialism and democracy. New York, USA: HarperCollins Publishers.

Scrase, I., \& Mackerron, G. (2009). Lock-in. In I. Scrace \& G. Mackerron (Eds.), Energy for the future energy, climate and the environment series. London: Palgrave Macmillan.

Seto, K. C., Davis, S. J., Mitchell, R. B., Stokes, E. C., Unruh, G., \& Urge-vorsatz, D. (2016). Carbon lockin: Types, causes, and policy implications. The Annual Review of Environment and Resources, 41(19), 1-28. https://doi.org/10.1146/annurev-environ-110615-085934.

Sewell, W. (1996). Three temporalities: Toward an eventful sociology. In T. J. McDonald (Ed.), The historic turn in the human sciences (pp. 245-280). University of Michigan Press.

Shim, J., Park, C., \& Wilding, M. (2015). Identifying policy frames through semantic network analysis: an examination of nuclear energy policy across six countries. Policy Sciences, 48, 51-83. https://doi. org/10.1007/s11077-015-9211-3.

Sovacool, B. K., \& Axsen, J. (2018). Functional, symbolic and societal frames for automobility: Implications for sustainability transitions. Transportation Research Part A: Policy and Practice, 118, 730-746. https://doi.org/10.1016/J.TRA.2018.10.008.

Sovacool, B. K., Axsen, J., \& Kempton, W. (2017). The future promise of vehicle-to-grid (V2G) integration: A sociotechnical review and research agenda. Annual Review of Environment and Resources, 42(1), 377-406. https://doi.org/10.1146/annurev-environ-030117-020220.

Sovacool, B. K., \& Hirsh, R. F. (2009). Beyond batteries: An examination of the benefits and barriers to plug-in hybrid electric vehicles (PHEVs) and a vehicle-to-grid (V2G) transition. Energy Policy, 37(3), 1095-1103. https://doi.org/10.1016/j.enpol.2008.10.005.

Steineke, J. M. (2007). Nordic topography of second homes. Journal of Nordregio, 7(3), 12-13.

Transport styrelsen. (2018). Frågor om supermiljöbilspremie. https:/www.transportstyrelsen.se/sv/vagtr afik/Miljo/Klimat/Miljobilar1/supermiljobilspremie1/. Accessed 5 Nov 2019.

Truffer, B., Murphy, J. T., \& Raven, R. (2015). The geography of sustainability transitions: Contours of an emerging theme. Environmental Innovation and Societal Transitions, 17, 63-72. https://doi. org/10.1016/j.eist.2015.07.004.

Turnheim, B., \& Geels, F. W. (2012). Regime destabilisation as the flip side of energy transitions: lessons from the history of the British coal industry (1913-1997). Energy Policy, 50, 35-49.

Unruh, G. (2000). Understanding carbon lock-in. Energy policy, 28(March), 817-830. https://doi. org/10.1016/S0301-4215(00)00070-7.

Vadén, T., Majava, A., Toivainen, T., Järvensivu, P., Hakala, E., \& Eronen, J. T. (2019). To continue to burn something? Technological, economic and political path dependencies in district heating in Helsinki. Finland. Energy Research \& Social Science, 58, 101270.

Valtioneuvosto. (2017). Kohti ilmastoviisasta arkea-Valtioneuvoston selonteko keskipitkän aikavälin ilmastopolitiikan suunnitelmasta vuoteen 2030.

Van den Bergh, J. C., \& Oosterhuis, F. (2008). An evolutionary-economic analysis of energy transitions. In E. Elgar (Ed.), Managing the transition to renwable energy: Theory and practice from local, regional and macro perspectives (pp. 149-173). UK: Cheltenham.

Vedung, E. (2017). Policy instruments: typologies and theories. In Carrots, sticks and sermons (pp. 21-58). Routledge.

Virki, T. (2019). Oslo to become first city to charge electric taxis over the air. Reuters. https://www.reute rs.com/article/us-norway-electric-taxis/oslo-to-become-first-city-to-charge-electric-taxis-over-the-airidUSKCN1R21ED. Accessed 5 Nov 2019.

Wells, P., \& Nieuwenhuis, P. (2012). Technological forecasting \& social change transition failure: Understanding continuity in the automotive industry, 79, 1681-1692. https://doi.org/10.1016/j.techf ore.2012.06.008. 
Winner, L. (2010). The whale and the reactor: A search for limits in an age of high technology. Chicago: University of Chicago Press.

Zauberman, G. (2003). The intertemporal dynamics of consumer lock-in. Journal of Consumer Research, $30(3), 405-419$.

Publisher's Note Springer Nature remains neutral with regard to jurisdictional claims in published maps and institutional affiliations. 